\section{PEER-REVIEWED ARTICLE}

Food Protection Trends, Vol 41, No. 2, p. 184-194 Copyright ${ }^{\mathscr{2}}$ 2021, International Association for Food Protection 2900 100th Street, Suite 309, Des Moines, IA 50322-3855
Jennifer Cripe* and Mary Losikoff

U.S. Food and Drug Administration, Center for Food Safety and Applied Nutrition, 5001 Campus Drive, College Park, MD 20740, USA

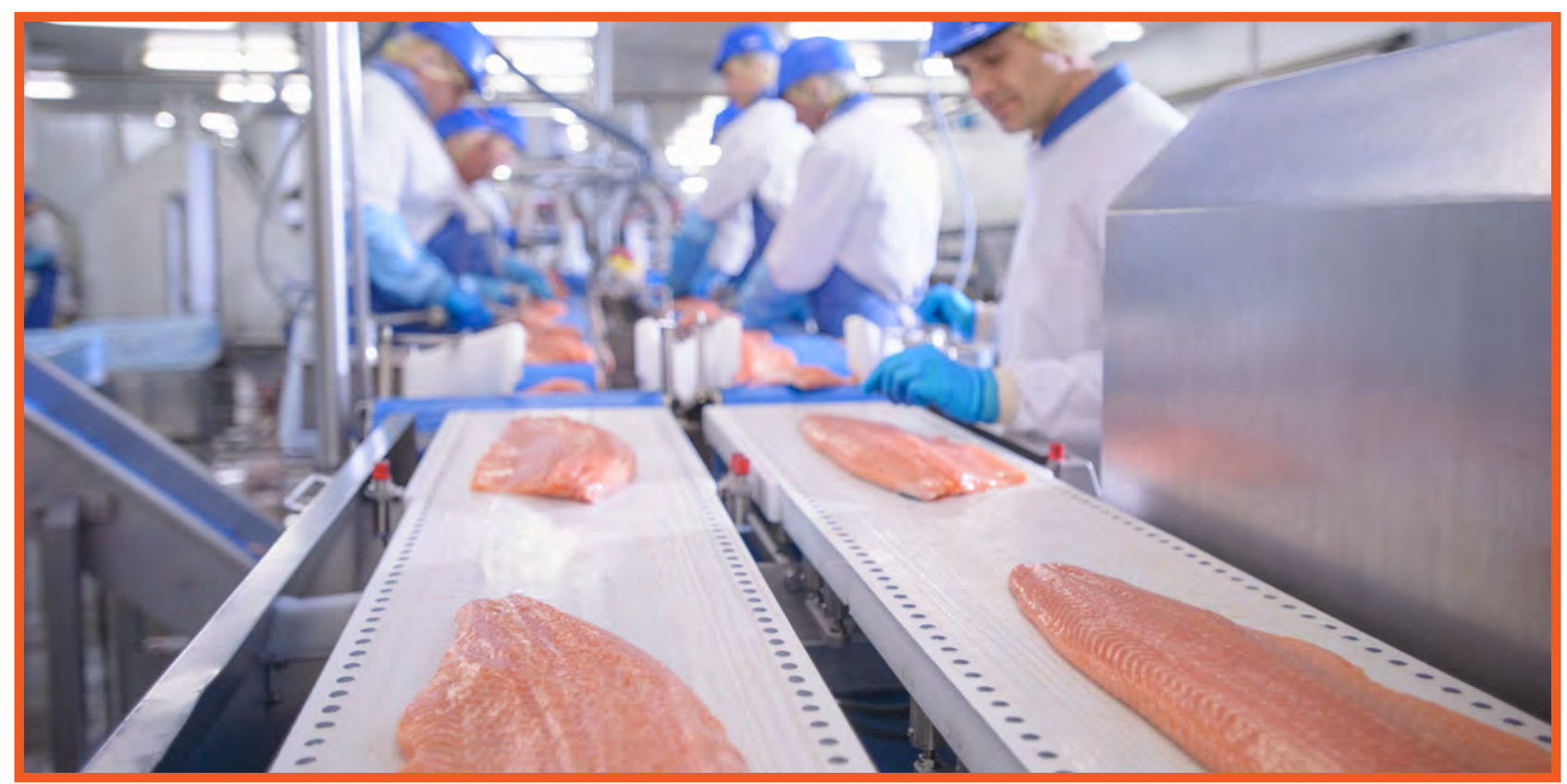

\title{
Presence of Listeria monocytogenes and Sanitation Controls in Cold-Smoked Salmon Facilities during FDA Inspections
}

\section{ABSTRACT}

The U.S. Food and Drug Administration (FDA) conducted inspections to observe operating practices and obtain data on the prevalence of Listeria monocytogenes in cold-smoked salmon processing facilities. FDA inspected and sampled 15 cold-smoked salmon processing facilities for Listeria spp. Environmental sampling showed that 13 facilities had one or fewer $L$. monocytogenes positive from each facility and two facilities had numerous (10 and 11, respectively] $L$. monocytogenes positives. The two facilities with numerous $L$. monocytogenes positives had gross insanitation and poor employee practices. One of these facilities had difficult-to-clean surfaces and inadequate cleaning and sanitizing; these likely contributed to cross-contamination, which led to the adulteration of cold-smoked salmon finished product by a resident strain of $L$. monocytogenes. The inspection results also showed that the three facilities where there was no detection of Listeria spp. routinely conducted environmental and finished product testing, frequently trained employees, and did routine cleaning and sanitizing. Overall, the results indicate that sanitation is of the utmost importance and that implementation of Listeria specific controls with environmental sampling should be done to prevent cold-smoked salmon from being adulterated by $L$. monocytogenes.

\section{INTRODUCTION}

The genus Listeria consists of several species, but L. monocytogenes is considered the species of most concern (23). L. monocytogenes causes the disease listeriosis and has a mortality rate of $20 \%$ (2). Listeriosis is a foodborne disease that can cause fever, diarrhea, nausea, and vomiting in healthy adults (14). More severe symptoms like bacteremia (infection in the blood) and meningitis (swelling of the brain) can occur in elderly and immunocompromised people (14). In pregnant women, the bacterium can pass through the placenta, leading to miscarriages (14). Uncertainty related to the relative pathogenicity of L. monocytogenes strains and the susceptibility of individual human hosts makes limiting exposure the best means of reducing infections (22). The U.S. Food and Drug Administration (FDA) considers readyto-eat food (RTE) contaminated with L. monocytogenes to be 
adulterated under section 402 (a) (1) of the Federal Food, Drug, and Cosmetic Act.

Listeria monocytogenes can grow with or without oxygen, at a maximum water phase salt of $10 \%$, a minimum $\mathrm{pH}$ of 4.4 , and minimum water activity of 0.92 (21). L. monocytogenes can grow at a minimum temperature of $-0.4^{\circ} \mathrm{C}\left(31.2^{\circ} \mathrm{F}\right)$ (21). In a survey of 130 samples from 13 lots of refrigerated, vacuum-packaged, cold-smoked salmon packed in six Danish smokehouses, the $\mathrm{pH}$ and water phase salt ranged from 6.1 to 6.3 and 3.5 to $8.9 \%$, respectively (7). These levels provide a suitable environment for the growth of L. monocytogenes. A review of six studies showed an exponential growth rate of 0.050 to $0.556 \log \mathrm{CFU} /$ day at $5^{\circ} \mathrm{C}\left(41^{\circ} \mathrm{F}\right)$ for L. monocytogenes inoculated in cold-smoked salmon (26). These results indicate that $L$. monocytogenes can grow throughout the shelf life of the product without temperature abuse.

Cold-smoked fish processing is a complex multistep process that relies on effective sanitation controls to prevent L. monocytogenes contamination (3). The heat applied during smoking is not sufficient to eliminate L. monocytogenes (e.g., FDA recommends smoking not exceed $32^{\circ} \mathrm{C}\left(90^{\circ} \mathrm{F}\right)$ ), and cold-smoked fish is considered a raw RTE food by FDA (20).

Environmental sampling and molecular typing methods, such as ribotyping, pulsed-field gel electrophoresis (PFGE), and, more recently, whole genome sequencing, have been used to compare isolates and subsequently identify routes of contamination, which can then lead to the design of control measures $(3,16)$. A 1994 review article of 11 studies reported that the overall prevalence of $L$. monocytogenes on cold-smoked fish was approximately $10 \%$, with the exception of two studies that found that 24 and $31 \%$ of the samples contained L. monocytogenes (1). Concern over the high prevalence of L. monocytogenes in cold-smoked fish led researchers to track the presence of L. monocytogenes in processing facilities using environmental sampling $(8,11$, 19). A 1995 environmental sampling study of six coldsmoked salmon processing plants concluded that the surface of frozen and fresh raw salmon was the primary source of L. monocytogenes contamination and that during processing this contamination was transferred to equipment, personnel, and other surfaces, which subsequently became secondary sources of contamination (8).

Other studies using environmental sampling with ribotyping have found that insanitation is the most likely source of finished product contamination $(11,19)$. In 2000, 512 environmental and 315 raw fish (whitefish, sablefish, and salmon) samples were collected from two cold-smoked fish processing plants (A and B) in the United States over two 8 -week periods (11). The results indicated that there was no significant statistical difference in the positive rate for L. monocytogenes in raw fish between plant A and plant $\mathrm{B}$, and the overall prevalence of $L$. monocytogenes for all raw fish was $14.6 \%$. However, the prevalence of L. monocytogenes in environmental samples from plant A was $43.8 \%$ and from plant B was $1.2 \%$. Ribotyping of isolates showed that some strains from the environmental samples were not detected in the raw fish samples and that persistent L. monocytogenes strains in the plant environment were the primary source of contamination of cold-smoked fish. The study concluded that (i) environmental contamination is largely separate from the incoming raw fish, (ii) persistent strains within the plant can be a continual source of contamination, and (iii) insanitation in the plant significantly contributes to L. monocytogenes contamination (11).

The importance of sanitation and L. monocytogenes control measures was further supported by a 2004 study of four cold-smoked salmon processing plants in the United States (19). A total of 234 raw fish, 233 finished products, and 533 environmental samples were collected monthly throughout 1 year. L. monocytogenes was isolated from $3.8 \%$ of the raw salmon and $1.3 \%$ of the cold-smoked salmon. This study used ribotyping of environmental samples to identify specific subtypes of L. monocytogenes and routes of contamination. The prevalence of L. monocytogenes in environmental samples from the four plants ranged from 0 to $30 \%$. Drains and nonfood contact surfaces were identified as the most frequently contaminated areas. This study found that the four plants received similar raw ingredients and produced similar finished products but varied in sanitation practices and procedures to prevent cross-contamination. Of the four plants, plant 1 had the highest prevalence of L. monocytogenes in environmental and finished product samples. The ribotyping data for plant 1 showed that transient subtypes were constantly being introduced into the plant by equipment, employees, and raw materials and also showed two persistent subtypes in the plant. One of the persistent subtypes of L. monocytogenes was found in floor drains, on the gloves of an employee, and, ultimately, in the finished product. In plant 2, although L. monocytogenes was not found in finished product, a persistent subtype was identified in the raw materials processing area that was also found on a door handle adjacent to the finished product area, indicating that cross-contamination from the raw materials area may have occurred. In plant 3, ribotyping data suggested that a niche in the floor mat harbored a persistent subtype of L. monocytogenes, which subsequently contaminated finished product. These results from plants 1, 2, and 3 showed the importance of effective cleaning and sanitization procedures to eliminate niches where L. monocytogenes persists and the importance of procedures to prevent cross-contamination. Plant 4 was substantially different from the other three plants in that L. monocytogenes was not isolated from environmental or finished product samples; it was observed that the floors and equipment had sufficient time to dry between processing times, indicating the importance of a dry processing environment. The study concluded that L. monocytogenes contamination in the processing environment was the most likely source of finished product contamination and that sanitation and L. monocytogenes control measures are critical. 
Some seafood processors use antimicrobial agents on raw RTE fish fillets before cold smoking to reduce pathogenic bacteria, including L. monocytogenes. Although antimicrobial agents can be highly effective (5-log reduction) to sanitize clean food contact surfaces, seafood processors should not rely solely on antimicrobial agents to eliminate or reduce Listeria on raw RTE salmon fillets. Whereas there is limited information in the scientific literature on the effectiveness of antimicrobial agents in reducing Listeria on raw fish fillets, three separate publications, one for acidified sodium chlorite (ASC) and two for ozone on salmon fillets, all showed $\leq 1-\log$ reduction $(5,6,17)$. Su and Morrissey (17) evaluated the use of a wash of $50 \mathrm{ppm}$ of ASC for $1 \mathrm{~min}$ on L. monocytogenes inoculated salmon fillets and found only a $0.52-\log$ reduction of L. monocytogenes; the authors suggested that the reduced efficacy of the ASC was probably due to reactions with organic substances, such as fish proteins. Crapo et al. (5) evaluated the efficacy of ozonated water at 0.6 to $1.5 \mathrm{ppm}$ to reduce Listeria innocua inoculated onto raw salmon fillets; they concluded that, whereas ozone can reduce bacterial levels in pure culture, it was not effective at reducing L. innocua ( $<1-\log$ reduction) on salmon filets. The authors also suggested that organic material, such as proteins, present on the surface of the fish fillets may react with the ozone in the water, reducing its effectiveness. Crowe et al. (6) evaluated the efficacy of ozone and found that the use of three spray passes of $1 \mathrm{mg} / \mathrm{L}(1 \mathrm{ppm})$ aqueous ozone generated a $1.17 \pm 0.04-\log$ reduction of Listeria inoculated on salmon fillets. Su and Morrissey (17) and Crapo et al. (5) emphasized the importance of preventing crosscontamination and of effective sanitation of food contact surfaces as critical control measures for L. monocytogenes.

Effective control measures for L. monocytogenes are especially important for smoked seafood processors. Smoked seafood was ranked as the fifth highest food category on a per serving basis for the risk of causing listeriosis in the 2003 FDA, U.S. Department of Agriculture risk assessment for L. monocytogenes (26). The risk assessment utilized data from 24 international and 6 domestic smoked seafood studies that showed that $13 \%$ of retail smoked seafood samples had detectable levels of L. monocytogenes. A preliminary determination of the risk assessment was a need for additional domestic data on the prevalence of L. monocytogenes in the United States. Concurrently, a 2003 publication by Gombas et al. (9) on RTE foods determined the presence and levels of L. monocytogenes in select retail foods from the United States to estimate consumer exposure and support the need for control strategies. This survey tested 31,705 food samples from retail firms in Maryland and California collected weekly from 2000 to 2001 . L. monocytogenes was found in $114(4.31 \%)$ of 2,644 smoked seafood samples. Enumeration of L. monocytogenes from the 114 positive samples showed that 78 samples had $\geq 1 \mathrm{CFU} / \mathrm{g}, 27$ ranged from $>1$ to $10^{2} \mathrm{CFU} / \mathrm{g}, 7$ ranged from $>10^{2}$ to $10^{4}$ $\mathrm{CFU} / \mathrm{g}$, and 2 ranged from $>10^{5}$ to $10^{6} \mathrm{CFU} / \mathrm{g}$.

A 2008 report on FDA's strategy to combat listeriosis indicated that the joint efforts of industry, government, consumers, and academia led to a reduction in the incidence of listeriosis in the United States from seven to three cases per million people between 1986 and 2006 (12). This report found that, from 1986 to 2006, fish was the most recalled food for contamination with $L$. monocytogenes.

More recently, a 2017 publication of a survey for L. monocytogenes in RTE foods suggested that the efforts of industry and regulators to control L. monocytogenes have contributed to a significant decrease in contaminated smoked seafood (13). This survey provided the results of 27,389 food samples collected weekly from supermarkets in California, Maryland, Connecticut, and Georgia from 2010 to 2013. The survey found L. monocytogenes in $2(0.27 \%)$ of 745 smoked seafood samples, which was significantly lower than the $4.31 \%$ prevalence published in 2003 by Gombas et al. (9). Enumeration of L. monocytogenes from the two positive samples showed a range of 9 to $250 \mathrm{CFU} / \mathrm{g}$, which is less than the maximum concentration of $1.5 \times 10^{5} \mathrm{CFU} / \mathrm{g}$ published by Gombas et al. (9). The authors suggested that this decrease in L. monocytogenes contamination was likely due to many factors, including industry practices and regulatory policies.

In January 2017, FDA issued the revised draft guidance for industry "Control of Listeria monocytogenes in Ready-toEat Foods." However, FDA continues to detect L. monocytogenes in RTE food processing areas, leading to numerous compliance actions. This paper offers insight into FDA inspections intended to identify controls and obtain data on the prevalence of L. monocytogenes within cold-smoked salmon facilities. Although these inspections were conducted in 2011, many of the observed insanitary conditions are similar to recent noncompliant inspections of seafood facilities where FDA found L. monocytogenes in RTE food processing areas. The findings and recommendations in this manuscript are relevant to all RTE food processors, especially seafood processors.

\section{MATERIALS AND METHODS}

FDA investigators conducted current good manufacturing practice (CGMP) inspections and environmental sampling for L. monocytogenes in 15 cold-smoked salmon facilities between July and December 2011. The objectives of the inspections were to identify current operating practices and controls and to obtain data on the prevalence of $L$. monocytogenes.

CGMP inspections were conducted according to $21 \mathrm{CFR}$ Part 110 and focused on the potential for cross-contamination of finished product from equipment, food contact surfaces, food, and employees (25). Investigators discussed sanitation procedures with management, reviewed their procedures if written, and observed employees during cleaning and sanitiz- 
ing. Investigators also documented procedures intended to reduce the potential for contamination of finished product from cross-contamination in the processing environment, such as product flow, employee practices, and the use of environmental sampling, to verify sanitation controls. The number of employees (i.e., an indication of facility size), employee training, and use of antimicrobial agents on fish prior to cold smoking were also recorded. This paper provides information on practices that were observed by a different investigator in each individual facility. This does not allow us to compare practices done in one facility to those in another facility to determine the significance of different practices to minimize cross-contamination.

Environmental samples (i.e., swabs) were collected from food contact surfaces and nonfood contact surfaces in close proximity to food and food contact surfaces (24). Approximately 50 to 100 swabs were collected at each facility. The number of swabs collected was based on the size of the facility. Environmental samples were taken several hours into production by swabbing surfaces such as food contact surfaces, smoking equipment, totes, cracks in the floor, floor drains, etc. In addition to environmental samples, finished product samples were collected from 2 of the 15 facilities. Swab and finished product samples were analyzed following the Bacteriological Analytical Manual method for the detection of Listeria (10). Samples found to contain Listeria spp. were speciated to determine whether the isolates were L. monocytogenes or a nonpathogenic species of Listeria. PFGE was performed on L. monocytogenes isolates using PulseNet's standardized protocol for L. monocytogenes (4).

\section{RESULTS}

\section{Environmental samples}

Table 1 summarizes the environmental sampling results and the number of employees in each of the 15 cold-smoked fish processing facilities inspected and sampled by FDA. The facilities varied in size from the smallest, with one part-time employee, to the largest, with 180 full-time employees and with additional employees hired seasonally. For discussion purposes, these 15 facilities were placed into four groups based on their environmental sample results.

\section{TABLE 1. FDA environmental swab results for Listeria spp. and $L$. monocytogenes positives and number of employees for each of the 15 cold smoked fish processing facilities}

\begin{tabular}{|c|c|c|c|c|c|c|}
\hline \multirow{2}{*}{ Facility } & \multirow{2}{*}{ Group $^{1}$} & \multirow{2}{*}{$\begin{array}{l}\text { Listeria spp. } \\
\text { Positives }\end{array}$} & \multirow{2}{*}{$\begin{array}{l}\text { L. monocytogenes } \\
\text { Positives }\end{array}$} & \multirow{2}{*}{$\begin{array}{l}\text { Nonpathogenic } \\
\text { Species of Listeria } \\
\text { Positives }\end{array}$} & \multicolumn{2}{|c|}{ Number of Employees } \\
\hline & & & & & Full-time & Part-time \\
\hline A & 1 & 0 & 0 & 0 & 35 & 25 \\
\hline $\mathrm{B}$ & 1 & 0 & 0 & 0 & 6 & 4 \\
\hline $\mathrm{C}$ & 1 & 0 & 0 & 0 & 22 & 0 \\
\hline $\mathrm{D}$ & 2 & 1 & 0 & 1 & 100 & 0 \\
\hline $\mathrm{E}$ & 2 & 1 & 0 & 1 & 0 & 1 \\
\hline $\mathrm{F}$ & 2 & 1 & 0 & 1 & 18 & 0 \\
\hline G & 2 & 3 & 0 & 3 & 180 & Seasonal \\
\hline $\mathrm{H}$ & 2 & 1 & 0 & 1 & 4 & 0 \\
\hline I & 3 & 2 & 1 & 1 & \multicolumn{2}{|c|}{ Not recorded } \\
\hline $\mathrm{J}$ & 3 & 1 & 1 & 0 & 6 & 0 \\
\hline $\mathrm{K}$ & 3 & 1 & 1 & 0 & 90 & 0 \\
\hline $\mathrm{L}$ & 3 & 1 & 1 & 0 & 4 & 0 \\
\hline $\mathrm{M}$ & 3 & 1 & 1 & 0 & \multicolumn{2}{|c|}{ Not recorded } \\
\hline $\mathrm{N}$ & 4 & 23 & 11 & 12 & 2 & 0 \\
\hline $\mathrm{O}$ & 4 & 12 & 10 & 2 & 35 & 0 \\
\hline
\end{tabular}

1. Group designation was based on FDA environmental sampling results for Listeria spp. and L. monocytogenes. 
TABLE 2. Sanitation practices used in each of the three facilities in Group 1 that had no Listeria spp. detected in FDA environmental samples

\begin{tabular}{c|c|l|l|c}
\hline Facility & $\begin{array}{c}\text { Written } \\
\text { sanitation } \\
\text { procedures }\end{array}$ & \multicolumn{1}{c|}{ Cleaning and sanitation practices } & Foot-baths & $\begin{array}{c}\text { Flow of processing } \\
\text { to prevent cross- } \\
\text { contamination }\end{array}$ \\
\hline A & Yes & $\begin{array}{l}\text { Full cleaning and sanitizing of food contact and } \\
\text { environmental surfaces throughout production and at } \\
\text { end of each production day with varying cleaning and } \\
\text { sanitizing chemicals. }\end{array}$ & Not observed & Yes \\
\hline B & Yes & $\begin{array}{l}\text { End of production debris removed, and food contact } \\
\text { surfaces scrubbed with brushes, warm water and } \\
\text { soap. Cleaning and sanitizing conducted again before } \\
\text { production. Utensils and removeable parts cleaned and } \\
\text { sanitized. Floor drains foamed three times a week. }\end{array}$ & Not observed & Not observed \\
\hline C & Not observed & $\begin{array}{l}\text { Entire area cleaned every four hours with foaming system. } \\
\text { Equipment disassembled washed, rinsed and sanitized. } \\
\text { Fixed equipment rinsed to remove debris, foamed, } \\
\text { scrubbed, hot water rinsed and sanitized. }\end{array}$ & Yes & Yes \\
\hline
\end{tabular}

\section{Observations}

Group 1, sanitation controls. All three facilities in group 1 (A, B, and C), which had no Listeria spp. detected in the environmental samples, routinely conducted environmental and finished product testing. All three facilities also provided frequent training for their employees on CGMP and food safety. Table 2 summarizes additional sanitation practices used in these three facilities.

Facility A had the most practices to minimize crosscontamination among the three facilities in group 1 . The flow of raw materials, finished product, and employees through the facility was controlled by sanitation procedures. The raw material receiving area, rinsing and salting area, curing cooler, and smoking room were separate from the smoked fish blast chiller and smoked fish processing area. Employees were restricted from moving among the various processing areas. Employees wore facility-provided boots, hair nets, and gloves in processing areas. To verify sanitation controls, facility A collected environmental samples weekly from six food contact surfaces and analyzed them for Listeria spp. The investigator's review of the facility's own environmental results showed no positives for Listeria spp. Facility B cleaned by scrubbing equipment with brushes and detergent and then by sanitizing both before and after production.

Group 1, insanitary conditions. Facility C had condensate, a common source of Listeria, dripping from a cooling unit onto exposed RTE finished product of cold-smoked salmon, which is an egregious sanitation deficiency. As an immediate corrective action, product was no longer stored under the condenser and management contacted a contractor to assess the cooling unit. The processor promised further corrective actions. The investigator did not describe the final disposition of the product; however, the adulterated product should have been destroyed or diverted to a nonfood use.

Group 2, environmental sample locations. The environmental sample results from the five facilities in group 2 (D, E, F, G, and $\mathrm{H}$ ) showed that Listeria spp. were detected without L. monocytogenes; this indicated that nonpathogenic stains of Listeria were isolated from sites that were in close contact or direct contact with product. These sites consisted of a fish brine rack, pin bone remover belt, handles of dry cure mixer, a basin of a stainless steel sink used for rinsing fish, and a crack in a processing room floor.

Group 2, sanitation controls. Facility D had the most documented practices to minimize cross-contamination among the 15 facilities inspected and sampled. The cleaning and sanitizing program included written procedures for equipment, coolers, tables, floors, walls, ceilings, drains, condensers, drip pans, etc. with monitoring records for specific daily, weekly, and monthly tasks. The food contact surfaces in the processing rooms were wiped down with 200 ppm of quaternary ammonia before employee breaks and lunch, with a full wet cleaning and sanitizing after production. Coolers were emptied and then cleaned and sanitized weekly (floors and walls) and monthly (ceilings and evaporators) by a designated cleaning crew. Employees wore clean lab 
coats, designated boots, hair nets, sleeve guards, and gloves. Hand wash and boot dip stations were located adjacent to the employee changing room. Additional boot dips and hand dips were strategically located throughout the facility, and the concentration of the sanitizer was tested by the quality control manager. A nonalkaline detergent was used in addition to an alkaline chlorinated foaming system. Peracetic acid and a quaternary ammonium were used to sanitize equipment. The flow of processing was done in one direction, from ingredients to finished product, that minimized potential cross-contamination of finished product. There was a physical separation of the finished product processing area from the other areas within the facility. Employee movement was restricted by using area-specific designated employees. Moveable equipment circulation was restricted by using areaspecific designated carts, pallet jacks, and trash receptacles. Finished products were stored in a separate cooler. The facility also had employee training upon hire and annually, with topics including GMP, hazard analysis and critical control point, chemicals, hand washing, food safety, Listeria controls, etc. Environmental samples were collected weekly from 10 sites on food contact surfaces and nonfood contact surfaces from high-risk areas. The environmental samples were analyzed for Listeria spp. by the quality control manager. The investigator's review of the facility's own environmental results for the previous 6-month period showed that Listeria spp.-positive results were found on a wire cart, floor drain, and slicer. The facility's documented corrective actions for the wire cart and floor drain positives included aggressive cleaning and sanitizing with disassembly and negative results for retesting of the affected and surrounding areas. The wire cart was eventually removed from service because it was determined by the facility to be hard to clean. The slicer was removed from service, aggressively cleaned and sanitized, and then retested with 10 additional swabs. Two Listeria spp. positives were also found by the firm from the area of (i) top and bottom sprockets on the toothed feed belt (lattice area) and (ii) platform. The lattice area was taken apart for more intense cleaning and sanitizing followed by retesting with six swabs that were negative. The next day the lattice area of the same slicer was sampled (six swabs) after soaking the entire unit in $200 \mathrm{ppm}$ of quaternary ammonia solution, and five swabs were positive. The lattice area was heat treated at $150^{\circ} \mathrm{F}$ $\left(65.6^{\circ} \mathrm{C}\right)$ for $2 \mathrm{~h}$, and the retesting results were negative.

Group 2, insanitary conditions. Facility E had condensate dripping onto a cooler floor near uncovered cooling coldsmoked fish. A hose with an affixed nozzle used to clean food contact surfaces was stored on a wet floor, allowing the potential for cross-contamination from the floor to food contact surfaces. Dried food debris was on the blades of the skinner and inside the grinder, indicating that the equipment was not properly cleaned after use. Conveyor belts on the finished product slicer were frayed and cracked, possibly making them difficult to clean and sanitize.
Facility $\mathrm{F}$ had condensate dripping from the condenser in the raw cooler in four different areas, creating four pools on the floor near uncovered salmon (not smoked). Also, in the finished product cooler there were two pools of standing water. Pools of water and condensate on floors have the potential to be contaminated with Listeria and to crosscontaminate wheels of moveable equipment, such as carts and forklifts, which can spread contamination throughout the facility. Additionally, when carts are pushed through pools of liquid on floors there is the potential for splash to crosscontaminate any food or items being conveyed on the carts. In this facility, the floors in the coolers and processing areas were cracked and pitted. Floors in disrepair have the potential to be difficult to clean and can create niches that harbor Listeria. Employees in facility F were observed wheeling garbage cans from the finished product processing area outside to the dumpster and then returning through multiple processing areas to the finished product processing area without cleaning and sanitizing the equipment.

Facility $\mathrm{H}$ had a significant number of flies in the processing room, and six flies were observed walking on a preparation table. Flies can carry pathogens and crosscontaminate food, food contact surfaces, and equipment.

Group 3, environmental sample locations. Environmental sample results from the five facilities in group 3 (I, J, K, L, and $\mathrm{M}$ ), which each had one swab with $L$. monocytogenes detected, showed that L. monocytogenes was isolated from drains, floors, and equipment in direct contact with the floor in four of the five facilities. In the fifth facility, L. monocytogenes was isolated from a wooden cutting board used as a food contact surface during packing of smoked fillets. This facility (L) was re-inspected by FDA to evaluate the implemented corrective actions for the detection of L. monocytogenes on a food contact surface (i.e., the wooden cutting board). The wooden cutting board had been discarded. Also, during the re-inspection, FDA collected 10 subsamples of cold-smoked salmon that were negative for L. monocytogenes and the facility was found to be in compliance with CGMP according to 21 CFR Part 110.

Group 3, insanitary conditions. In group 3, four of the five facilities did not have any significant objectionable observations during the inspection. The fifth facility (I) had three CGMP deficiencies related to plumbing, floors, walls, and ceilings that warranted voluntary action.

Group 4, facility $N$ environmental sample locations. Results of environmental sampling from facility $\mathrm{N}$ showed that Listeria spp. were detected in 23 swabs from the 78 collected. After further testing of the 23 Listeria spp. isolates, 11 were found to be L. monocytogenes and 12 were nonpathogenic Listeria species. Nonpathogenic Listeria species were isolated from four legs of processing tables, two legs of brine tanks, two brine tank drains, the bottom of a brine tank, the front of a processing table, a strip curtain, and a metal basket on the floor used to hold fish waste. L. monocytogenes was found in a 
brine tank drain, in the bottom of a brine tank, on two legs of processing tables, in five areas on the floor, and in two floor drains in the processing areas.

Group 4, facility $N$ insanitary conditions. Totes used to keep fish immersed in the brine solution were soiled and stored on the wet floor. Totes constructed with holes in the bottom used for holding fish were placed on cardboard that had been previously stepped on by employees. The fans used to dry the fish after brining were visibly dirty. There was rust on the ceiling in the walk-in cooler above exposed stored fish. A box of salt used during brining of the fish was stored on top of a floor drain. All of these sanitation issues were corrected before the inspection was completed. The firm did not have any procedures for environmental sampling.

Group 4, facility $O$ environmental sample locations (initial inspection). Environmental sampling results from facility O showed that Listeria spp. were detected in 12 swabs from the 78 collected. After further testing of the 12 Listeria spp. isolates, 10 were found to be L. monocytogenes and 2 were nonpathogenic Listeria species. L. monocytogenes was detected on (i) a paddle used to agitate thawing fish, (ii) the bottom rack of a cart in the brine cooler, (iii) a brine tank drain spout, (iv) the exterior door handle on the smoker cooler, (v) the rubber strip on the interior of the brine cooler door, (vi) the rubber grip areas on the top handles of two step ladders (brining area), (vii) the front and (viii) rear forklift wheels (thaw area), (ix) the exterior strip along the base of the thaw room door, and (x) a rope attached to the thaw room door used to lower the roll-up door.

Group 4, facility $O$ sanitation controls (initial inspection). Facility $\mathrm{O}$ had ozonated water for thawing fish, quaternary ammonium hand dips, fogs for equipment, foot dips, foaming floor sprays, peracetic floor wash, quarterly employee training, an environmental testing plan for Listeria spp., and finished product testing for L. monocytogenes. The investigator's review of the facility's own routine weekly environmental sampling over a 10-month period prior to the inspection showed that Listeria spp. were detected on two separate sampling dates from the floor in the brining room and the floor near a freezer. The firm's corrective actions included cleaning with chlorine solution, steam cleaning, and sanitizing with quaternary ammonia solution, followed by the collection of additional swabs over three consecutive days.

The firm's results showed that Listeria spp. were not detected in the swabs taken after this intense cleaning and sanitizing.

Group 4, facility $O$ insanitary conditions (initial inspection). During the inspection, investigators observed poor employee practices. For example, employees sprayed and cleaned brining bins in a manner that generated splash and spray, which contacted the floor near fish that was ready to enter the smoker; this created the potential for cross-contamination from the floor. Carts of packaged finished product were stored under cooling units that were dripping condensation. An employee was observed dragging their smock across the finished product processing floor for several feet while leaving on break.

Group 4, facility O first re-inspection. Facility $\mathrm{O}$ was reinspected due to the detection of L. monocytogenes on a food contact surface (the bottom rack of a cart in the brine cooler holding exposed salmon fillets on above racks). During the re-inspection, the firm provided information on their corrective actions for the previous inspection, which consisted of cleaning and documentation of sanitation improvements. Additionally, the FDA investigators observed employees handling processing clothing properly without contacting the floor, and the cooler had been reorganized to prevent product from being stored under the cooler unit where dripping condensation was previously observed. The firm also replaced their totes with disposable totes, replaced drain covers in the fish fillet area, added additional foot dips, sanitized brining utensils, and started periodically spraying step ladders with chlorine.

Additional environmental sampling conducted by FDA showed that L. monocytogenes was detected in 8 swabs of the 96 analyzed. L. monocytogenes was isolated from (i) a rubber grip area on the top handle of a step ladder in the brine area, (ii) a taped area on the top handle of a step ladder in the brine area, (iii) a rubber strip on the base of the brining room door, (iv) a wheel of a pallet jack, (v) a paddle with rivets used to stir brine, (vi) an in-floor scale in the fillet area, (vii) the front wheel of a pallet jack in the RTE food processing area, and (viii) rack surfaces in the finishing cooler.

Finished product samples collected by FDA were found to be contaminated by L. monocytogenes. The firm voluntarily recalled the product. PFGE conducted by FDA showed that the L. monocytogenes isolated during the initial inspection was indistinguishable from the isolate obtained during the first re-inspection. This indicates that the facility's cleaning, sanitizing, and corrective actions were not sufficient to eliminate the pathogen and a resident strain of L. monocytogenes was established in the facility. These results also suggest that the rubber grip and taped areas on the step ladders may have been difficult to clean surfaces that created niches for the harborage of L. monocytogenes and that the firm's corrective action of periodically spraying the step ladders with chlorine did not eliminate the pathogen. The PFGE conducted by FDA also showed that L. monocytogenes isolated from the finished product was indistinguishable from the environmental samples. This indicates that the contamination most likely occurred from cross-contamination within the facility.

Group 4, facility $O$ second re-inspection. A second re-inspection was conducted because FDA detected L. monocytogenes in environmental and finished product samples during the first re-inspection. Once again, FDA evaluated CGMPs, collected environmental and finished product samples, verified sanitation and process changes since the first re-inspection, and reviewed the firm's environmental testing records. The 


\begin{tabular}{|c|c|c|c|c|}
\hline Facility & Group & Antimicrobial agents used on fish & $\begin{array}{c}\text { Safe and } \\
\text { suitable use of } \\
\text { antimicrobial } \\
\text { agents }\end{array}$ & $\begin{array}{c}\text { Listeria spp } \\
\text { positives }\end{array}$ \\
\hline A & 1 & Chlorine dioxide rinse $25 \mathrm{ppm}$ & No & 0 \\
\hline B & 1 & Peracetic acid $<160 \mathrm{ppm}$ and Chlorine dioxide $40-50 \mathrm{ppm}$, separately & No & 0 \\
\hline $\mathrm{D}$ & 2 & ASC rinse $40-50 \mathrm{ppm}$ for 5 minutes with subsequent water rinse & Yes & 1 \\
\hline $\mathrm{E}$ & 2 & Quaternary ammonium $150 \mathrm{ppm}$ & No & 1 \\
\hline G & 2 & Fillets thawed in ASC at 2-5 ppm with subsequent water rinse & Yes & 3 \\
\hline $\mathrm{L}$ & 3 & ASC rinse $100 \mathrm{ppm}$ for $<15$ minutes, no subsequent water rinse & No & 1 \\
\hline M & 3 & ASC rinse $40-50$ ppm for $30-60$ minutes, no subsequent water rinse & No & 1 \\
\hline $\mathrm{O}$ & 4 & Ozonated water rinse & Yes & 12 \\
\hline
\end{tabular}

(ASC) Acidified Sodium Chlorite

firm documented the disposal of the difficult to clean step ladders and the riveted paddle used in brining that were found to be contaminated with L. monocytogenes by FDA. The firm continued their own environmental sampling and began holding finished product until test results were negative for L. monocytogenes. The firm's own environmental testing results were all negative for $L$. monocytogenes. The environmental and finished product samples collected by FDA during the second re-inspection were negative for Listeria spp., and the inspection was classified as voluntary action indicated.

\section{Use of antimicrobial agents on fish}

Any substance used on fish needs to be safe and suitable for use and in compliance under the applicable regulation. The use of antimicrobial agents on fish before smoking was documented in some of the facilities during the inspections of the 15 facilities (Table 3). It is important for seafood processing facilities to comply with FDA regulations (including specifications and conditions of safe use) or to comply with the conditions of safe use of a generally recognized as safe substance when using permitted antimicrobial agents in processing seafood. For example, there are health concerns in regard to possible residues of chlorite and chlorate on treated seafood, or possible mutagenic and carcinogenic reaction products that may result from misuse of chlorine dioxide and ASC directly on food (18). FDA considers food treated with antimicrobial agents in an unauthorized manner to be in violation of the law and potentially unsafe.
Of the 15 facilities inspected, eight used antimicrobial agents on fish (Table 3). Of these eight facilities, five (A, B, $\mathrm{E}, \mathrm{L}$, and $\mathrm{M}$ ) used antimicrobial agents in a manner that did not conform with authorized uses. Facility A inappropriately used a 25-ppm chlorine dioxide rinse that exceeds the limit of $3 \mathrm{ppm}$ listed in effective food contact notifications for chlorine dioxide use on seafood. Facility $B$ inappropriately used a rinse of $<160 \mathrm{ppm}$ of peracetic acid followed by a 40 - to 50 $\mathrm{ppm}$ chlorine dioxide rinse on fish. There is no food additive regulation nor a food contact notification allowing the use of peracetic acid by itself on seafood. Additionally, the use of 40 to $50 \mathrm{ppm}$ of chlorine dioxide exceeds the limit of $3 \mathrm{ppm}$ listed in effective food contact notifications for chlorine dioxide use on seafood. Facility E inappropriately used $150 \mathrm{ppm}$ of quaternary ammonium on fish. Quaternary ammonium is approved for use on processing equipment and food contact surfaces, but not as an antimicrobial agent on seafood.

Four facilities (D, G, L, and M) used ASC as an antimicrobial agent in water to rinse fish. ASC can be used to rinse seafood in accordance with current industry standards at a concentration of 40 to $50 \mathrm{ppm}$ of sodium chlorite when followed by a potable water rinse prior to consumption for fish that is intended to be consumed raw (e.g., cold-smoked fish), per 21 CFR 173.325 (d)(1). Of the four facilities, two (D and G) used ASC in accordance with food additive regulations under $21 \mathrm{CFR} 173$. ASC use was inappropriate in facilities $\mathrm{L}$ and $\mathrm{M}$ because treated fish was not subjected to a water rinse as required for cold-smoked fish. Additionally, facility L used $100 \mathrm{ppm}$ of ASC, which exceeds the concentrations of 40 to $50 \mathrm{ppm}$ listed in 21 CFR 173.325 (d)(1). 
Facility $\mathrm{O}$ used ozonated water to rinse fish. Ozone in water can be used as an antimicrobial agent on food, including seafood, in accordance with the regulations under 21 CFR Part 173.368.

\section{DISCUSSION}

Facilities $\mathrm{N}$ and $\mathrm{O}$ were found by FDA to have a higher prevalence of L. monocytogenes ( 11 and 10 positives, respectively). Facilities $\mathrm{N}$ and $\mathrm{O}$ were also found to have several insanitation observations, such as uncontrolled dripping condensate, cross-contamination, and an ineffective or no environmental sampling program.

During the initial inspection, facility $\mathrm{O}$ had carts of packaged finished product stored under cooling units that were dripping condensation, a common source of Listeria. Sanitation monitoring for the prevention of adulteration of food, food packing material, and food contact surfaces by condensate is required in 21 CFR 123.11 (b)(5). Corrective actions need to ensure that no product enters commerce that is either injurious to health or is otherwise adulterated, in addition to correcting the cause of the problem (e.g., elimination of condensation, repair or maintenance of condenser). The cooler was reorganized to prevent product from being stored under the cooler unit where dripping condensation was previously observed. However, although moving product away from dripping condensate is an acceptable immediate and preliminary correction, this correction does not correct the cause of the uncontrolled dripping condensate.

Facility $\mathrm{O}$ was found by FDA to have L. monocytogenes in 10 environmental samples in the initial inspection and in eight environmental samples and finished product in the first re-inspection. The environmental sampling results showed that the firm had inadequate cleaning and sanitizing because the step ladders used in the brining area to place fish on trays into racks for the smoker that were found positive during the initial inspection were still contaminated with L. monocytogenes in the first re-inspection. The PFGE conducted by FDA showed that a resident strain of L. monocytogenes was established in the facility and that L. monocytogenes isolated from the finished product most likely occurred from crosscontamination within the facility. Although facility $\mathrm{O}$ had several sanitation controls in place, it appears that the firm's use of ozonated water on raw product and chemicals on food contact surfaces and floors did not compensate for the insanitary practices.

Facility $\mathrm{O}$ appeared to have an ineffective environmental sampling plan. In view of FDA detecting 10 L. monocytogenes positives in one sampling and the firm detecting only two positives over a 10-month period, it appears that the firm's environmental sampling was ineffective. Firms should routinely examine their sampling frequency and timing of collection along with the number and location of samples collected.
Environmental sampling should be conducted to verify the effectiveness of cleaning and sanitizing and to identify and eliminate harborages of L. monocytogenes (15). L. monocytogenes may not be eliminated by routine sanitization because it is capable of producing biofilms and persisting in processing facilities by establishing harborages and niches (3). Processors should sample after several hours of production to allow harborages to loosen and L. monocytogenes to be dislodged (15). Sampling immediately following cleaning and sanitizing can result in consistently negative results and a failure to identify harborages (15). Processors should also test environmental samples for the presence of Listeria spp. Although L. monocytogenes is the most concerning species of Listeria that causes human illness, the presence of Listeria spp. is often used to identify conditions conducive to the presence and growth of L. monocytogenes $(3,15)$. FDA's draft guidance for industry "Control of Listeria monocytogenes in Ready-to-Eat Foods" recommends that processors test environmental samples for the presence of Listeria spp. without determining whether L. monocytogenes is present (23). Testing for Listeria spp. detects both $L$. monocytogenes and the more common nonpathogenic species $(15,23)$. To ensure that Listeria control measures eliminate harborages of Listeria, processors should conduct robust environmental sampling with a "seek and destroy" mentality (23). The draft guidance recommends that processors determine the appropriate number of sampling sites based on the size of the plant, plant features, product flow, characteristics of the RTE food, the processing methods used to produce the food, and any previous sampling results. Even the smallest processors should collect weekly samples after several hours of production from at least five food contact surfaces and five nonfood contact surfaces on each RTE production line of food that supports the growth of L. monocytogenes (e.g., cold-smoked salmon). Additionally, the draft guidance recommends that all food contact surfaces be tested at least once each month and all nonfood contact surfaces at least once each quarter. With this amount of sampling, processors should expect to detect Listeria spp. occasionally in a few environmental samples and be ready with appropriate corrective actions based on location.

Sampling food contact surfaces and taking appropriate corrective actions is critical due to the risk of contaminating food. During the initial inspection, facility $\mathrm{O}$ was found by FDA to have L. monocytogenes on a food contact surface (the bottom rack of a cart in the brine cooler holding exposed salmon fillets on above racks). The firm's corrective actions included cleaning and documentation of sanitation improvements. When L. monocytogenes is detected on food contact surfaces, such as racks, carts, utensils, brining tanks, and cutting boards, FDA recommends that processors implement corrective actions that address both the facility and the food (23). Facility-related corrective actions should 
include intensified cleaning and sanitizing with disassembly of equipment, intensified environmental sampling of affected and surrounding areas, and correction of any conditions or procedures that led to the contamination. Food-related corrective actions should include segregation and holding of any food that may have had contact with the contaminated food contact surface. Processors should then decide what to do with the affected food. FDA recommends the product be reprocessed with a listericidal control measure (e.g., a cook that eliminates L. monocytogenes), destroyed, or diverted to a use in which it will not be consumed by humans or animals. If product has entered commerce, processors should initiate a recall.

Facility $\mathrm{N}$ was found by FDA to have L. monocytogenes in a brine tank drain, on the bottom of a brine tank, on two legs of processing tables, in five areas on the floor, and in two floor drains in the processing areas. These environmental sampling results indicate that the nonfood contact surfaces of floor, floor drains, and equipment in contact with the floor were potential sources of $L$. monocytogenes contamination. Nonfood contact surfaces can be a potential source of contamination, and having adequate corrective actions is important. Drains are a composite of what can be found in the room and are a hospitable environment for Listeria (15). When Listeria is detected in drains, processors should correct any conditions that led to the contamination, including evaluation of drain design and function; conduct additional environmental sampling; clean and sanitize the area; and ensure that procedures are in place to prevent the spread of contamination (23). Although surfaces such as floors, drains, and wheels of a pallet jack or cart are not food contact surfaces, these surfaces are important because insanitary actions by employees can spread the contamination to food contact surfaces or food (23). For example, contamination on the floor could be transferred to food contact surfaces by water splash and spray or by placing items, such as boxes and hoses, on food contact surfaces after they have been in direct contact with the floor. When Listeria spp. are detected on nonfood contact surfaces that are in close proximity to food and food contact surfaces, FDA recommends that processors implement corrective actions that include cleaning and sanitizing, environmental sampling of affected and surrounding areas, and correction of any conditions or procedures that led to the contamination (23). Additionally, FDA recommends that sanitation procedures be intensified when Listeria spp. are detected on several nonfood contact surfaces that are in close proximity to food and food contact surfaces during the same sampling period. This is because the routine sanitation procedures are likely inadequate, and Listeria spp. may have become established in one or more harborages (23).

\section{CONCLUSION}

The inspections showed a low prevalence of L. monocytogenes ( $\leq 1$ positive) in each of the 13 of 15 cold-smoked salmon processing facilities sampled by FDA. Two facilities ( $\mathrm{N}$ and $\mathrm{O}$ ) had a higher prevalence of L. monocytogenes (11 and 10 positives, respectively). Facility $\mathrm{N}$ had 11 L. monocytogenes and 12 nonpathogenic species of Listeria positives, mostly from the floor, floor drains, and equipment in contact with the floor. The facility had no environmental sampling program, and their most significant insanitary conditions were poor employee practices that likely led to Listeria spp. cross-contamination from the floor to equipment. Facility $\mathrm{O}$ had gross insanitation, poor employee practices, difficult to clean surfaces, and inadequate cleaning and sanitizing that likely contributed to cross-contamination, resulting in the adulteration of coldsmoked salmon from a resident strain of $L$. monocytogenes. In addition, the facility's use of antimicrobial agents on raw product, food contact surfaces, and floors did not compensate for the insanitary practices observed during the inspection.

The results also showed that three facilities (A, B, and C), where there was no detection of Listeria spp., routinely conducted environmental and finished product testing and had frequent employee training in addition to routine cleaning and sanitizing. Overall, the results show that to minimize the potential for L. monocytogenes contamination, it is necessary to have comprehensive practices that include sanitation that prevents contamination of food and food contact surfaces, sanitary employee practices, appropriate corrective actions, and environmental sampling to identify and eliminate niches where L. monocytogenes can persist.

\section{ACKNOWLEDGMENTS}

The authors are appreciative of FDA investigators that conducted the inspections and collected environmental samples. The authors also thank the following FDA, Center for Food Safety and Applied Nutrition employees for their thoughtful review of the manuscript: Jenny Scott, Senior Advisor to the Director, Office of Food Safety; Mickey Parish, Senior Science Advisor, Office of the Center Director, and Lane Highbarger and Molly Harry, Consumer Safety Officers, Office of Food Additive Safety.

\section{REFERENCES}

1. Ben Embarek, P. K. 1994. Presence, detection and growth of Listeria monocytogenes in seafoods: a review. Int. J. Food Microbiol. 23:17-34.

2. Bennion, J. R., F. Sorvillo, M. E. Wise, S. Krishna, and L. Mascola. 2008. Decreasing listeriosis mortality in the United States, 1990-2005. Clin. Infect. Dis. 47:867-874.
3. Busta, F. F., G. E. Bledsoe, G. J. Flick, L. Gram, D. Herman, M. L. Jahncke, and D. R. Ward. 2001. Processing parameters needed to control pathogens in cold-smoked fish. J. Food Sci. 66(Suppl.):S1055-S1134. Available at: https://www.fda.gov/Food/ FoodborneIllnessContaminants/ucm545157. htm. Accessed 15 May 2020.
4. Centers for Disease Control and Prevention. 2013. Standard operating procedure for PulseNet PFGE of Listeria monocytogenes. Available at: https://www.cdc.gov/pulsenet/ pathogens/pfge.html. Accessed 15 May 2020. 
5. Crapo, C., B. Himelbloom, S. Vitt, and L. Pedersen. 2004. Ozone efficacy as a bactericide in seafood processing. J. Aquat. Food Prod. Technol. 13:111-123.

6. Crowe, K., D. Skonberg, A. Bushway, and S. Baxter. 2012. Application of ozone sprays as a strategy to improve the microbial safety and quality of salmon fillets. Food Control 25:464-468.

7. Dalgaard, P., and L. V. Jorgensen. 1998. Predicted and observed growth of Listeria monocytogenes in seafood challenge tests in naturally contaminated cold-smoked salmon. Int. J. Food Microbiol. 40:105-115.

8. Eklund, M. W., F. T. Poysky, R. N. Paranjpye, L. C. Lashbrook, M. E. Peterson, and G. A. Pelroy. 1995. Incidence and sources of Listeria monocytogenes in cold-smoked fishery products and processing plants. J. Food Prot. 58:502-508.

9. Gombas, D. E., Y. Chen, R. S. Clavero, and V. N. Scott. 2003. Survey of Listeria monocytogenes in ready-to-eat foods. J. Food Prot. 66:559-569.

10. Hitchins, A. D., K. Jinneman, and Y. Chen. 2016. Detection and enumeration of Listeria monocytogenes in foods, chap. 10. In Bacteriological analytical manual. Available at: https://www.fda.gov/food/laboratorymethods-food/bam-detection-and-enumeration-listeria-monocytogenes. Accessed 15 May 2020.

11. Hoffman, A. D., K. L. Gall, D. M. Norton, and M. Wiedmann. 2003. Listeria monocytogenes contamination patterns for the smoked fish processing environment and for raw fish J. Food Prot. 66:52-60.

12. Klontz, K. C., P. V. McCarthy, A. R. Datta, J. O. Lee, D. W. K. Acheson, and R. E. Brackett. 2008. Role of the U.S. Food and Drug Administration in the regulatory management of human listeriosis in the United States. J. Food Prot. 71:1277-1286.

13. Luchansky, J. B., Y. Chen, A. C. Porto-Fett, R. Pouillot, B. A. Shoyer, R. JohnsonDeRycke, D. R. Eblen, K. Hoelzer, W. K. Shaw, Jr., J. M. van Doren, and M. Catlin. 2017. Survey for Listeria monocytogenes in and on ready-to-eat foods from retail establishments in the United States (2010 through 2013): assessing potential changes of pathogen prevalence and levels in a decade. J. Food Prot. 80:903-921.
14. Rocourt, J., C. Jacquet, and A. Reilly. 2000. Epidemiology of human listeriosis and seafoods. Int. J. Food Microbiol. 62:197-209.

15. Scott, V. N., M. Wiedmann, D. Hicks, R. Collette, M. L. Jahncke, and K. Gall. 2005. Guidelines for Listeria testing of environmental, raw product and finished product samples in smoked seafood processing facilities. Food Prot. Trends 25:23-34.

16. Stasiewicz, M. J., H. F. Oliver, M. Wiedmann, and H. C. den Bakker. 2015. Whole-genome sequencing allows for improved identification of persistent Listeria monocytogenes in foodassociated environments. Appl. Environ. Microbiol. 81:6024-6037.

17. Su, Y., and M. Morrissey. 2003. Reducing levels of Listeria monocytogenes contamination on raw salmon with acidified sodium chlorite. J. Food Prot. 66:812-818.

18. Taylor, J. B., and D. W. Wohlers. 2004. Toxicological profile for chlorine dioxide and chlorite. U.S. Environmental Protection Agency, Washington, D.C. Available at: https://stacks.cdc.gov/view/cdc/37580. Accessed 15 May 2020

19. Thimothe, J., K. Kerr Nightingale, K. Gall, V.N. Scott, and M. Wiedmann. 2004. Tracking of Listeria monocytogenes in smoked fish processing plants. J. Food Prot. 67:328-341.

20. U.S. Food and Drug Administration. 2011. Fish and fishery products hazards and controls guidance, chap. 13. Available at https://www.fda.gov/food/ seafood-guidance-documents-regulatoryinformation/fish-and-fishery-productshazards-and-controls-guidance-4th-edition. Accessed 15 May 2020.

21. U.S. Food and Drug Administration. 2011. Fish and fishery products hazards and controls guidance. Appendix 4. Available at https://www.fda.gov/food/ seafood-guidance-documents-regulatoryinformation/fish-and-fishery-productshazards-and-controls-guidance-4th-edition. Accessed 15 May 2020
22. U.S. Food and Drug Administration. 2012. Listeria monocytogenes. In Bad bug book: handbook of foodborne pathogenic microorganisms and natural toxins, 2 nd ed. Available at https://www.fda.gov/food/ foodborne-pathogens/bad-bug-book-secondedition. Accessed 15 May 2020.

23. U.S. Food and Drug Administration. 2017. Draft guidance for industry: control of Listeria monocytogenes in ready-to-eat foods. Available at: https://www.fda.gov/ regulatory-information/search-fda-guidancedocuments/draft-guidance-industry-controllisteria-monocytogenes-ready-eat-foods. Accessed 15 May 2020.

24. U.S. Food and Drug Administration. 2020 Sampling: collection technique, subchap. 4.3. In Investigations operations manual. Available at: https://www.fda.gov/inspectionscompliance-enforcement-and-criminalinvestigations/inspection-references/ investigations-operations-manual. Accessed 2 October 2020.

25. U.S. Food and Drug Administration. 2020. Establishment inspections: food, subchap. 5.4. In Investigations operations manual. Available at https://www.fda. gov/inspections-compliance-enforcementand-criminal-investigations/inspectionreferences/investigations-operations-manual. Accessed 2 October 2020.

26. U.S. Food and Drug Administration and U.S. Department of Agriculture. 2003. Quantitative assessment of the relative risk to public health from foodborne Listeria monocytogenes among selected categories of ready-to-eat foods. Available at: https:// www.fda.gov/food/cfsan-risk-safetyassessments/quantitative-assessmentrelative-risk-public-health-foodborne-listeriamonocytogenes-among-selected. Accessed 15 May 2020 